\title{
Señderos
}

\section{Educar en contra del olvido Pedagogía y Memoria ${ }^{1}$}

\author{
Educating against oblivion \\ Pedagogy and Memory
}

\section{Autora: \\ Isabel Cristina Vélez Restrepo ${ }^{2}$ \\ Recibido: 12 de mayo de 2017 \\ Aprobado: 30 de mayo de 2018}

1. Artículo resultado de la investigación "Globalización neoliberal y crisis de la educación", adscrito a la Línea de investigación: Desarrollo Humano y Contextos Educativos de la Universidad de San Buenaventura Medellín. El proyecto inició el 20 de agosto de 2015 y finalizó el 25 de agosto de 2017. 2. Licenciada en Básica Primaria, con énfasis en Humanidades y Lengua Castellana. Magíster en Ciencias de la Educación. Correo electrónico: cristinavelez.restrepo@gmail.com

\section{Resumen}

El presente artículo propone enfocarse en la diferencia que presenta la pedagogía y la memoria, y cómo se da la relación y reflexión de la memoria misma con la historia. El problema se sitúa en el olvido, al explicar que las prácticas pedagógicas se basan en el mismo olvido, en el sufrimiento y en el daño que vive el hombre de hoy. Para ello, se retoman planteamientos de Benjamin, en la concepción de memoria e historia, y posturas de otros autores que aportan al desarrollo de la temática: Educar contra el olvido: pedagogía y memoria.

Palabras clave: Educación, memoria, olvido, pedagogía, historia, tradición. 


\begin{abstract}
This article proposes to focus on the difference presented by pedagogy and memory, and how the relationship and reflection of memory itself with history occurs. The problem lies in oblivion, explaining that pedagogical practices are based on the same forgetfulness, suffering and harm that modern man
\end{abstract}

experiences. To this end, Benjamín's approach is taken up, in the conception of memory and history, and positions of other authors that contribute to the development of the theme: Educate against oblivion: pedagogy and memory.

Keywords: Education, memory, oblivion, pedagogy, history, tradition.

\section{Introducción}

El tema de la memoria ha logrado recientemente un tratamiento más sistemático dentro de los estudios de la violencia, el olvido y la tradición. Además, existen grandes debates en torno al pasado que efectúan una enorme cantidad de discusiones provenientes del ámbito académico. Estos revelan tensiones en relación con la configuración de los relatos del pasado en los que intervienen representaciones históricas que entran en el problema de la formación. La historia se muestra como un terreno inestable en el que entran situaciones políticas que afectan la educación. Consideraciones en torno al pasado: quién, qué y de qué modo las sociedades deben recordar.

En el desarrollo del artículo se abordan autores importantes que llevan a la reflexión del tema en cuestión; algunos son: Benjamin (2012), Mate (2003), Butler (2006), Hincapié García (2016) y Piñeres Sus (2016). El problema que se trabaja es el olvido en educación, ya que las prácticas pedagógicas se basan en el olvido, en el sufrimiento y en el daño. Este artículo es un producto asociado a la investigación "Globalización neoliberal y crisis de la educación” (Márquez y Vélez, 2017). El enfoque que desarrolla dicha investigación se denomina hermenéutico crítico-reconstructivo (Prior et al., 2002; Muñoz et al., 2010), porque se caracteriza por la reflexibilidad, la racionalidad de la comprensión y la reconstrucción (Escobar e Hincapié, 2017). Además, la modalidad investigativa está planteada a partir del análisis de contenido, apoyada en la mirada de Avela (2000), por lo que manifiesta que este ejercicio se dirige a la interpretación de textos, escritos o grabados, filmados u otra forma diferente, donde puedan existir toda clase de registros de datos, entre otros.

La primera parte del artículo presenta la reflexión entre los conceptos de pedagogía y memoria y la relación memoria historia, con el objetivo de comprender el valor de la memoria en la educación. En la segunda y última parte se explica por qué no se debe olvidar el pasado, por qué se deben tener presentes las huellas que dejaron los oprimidos como un propósito en la formación del hombre. 


\title{
Pedagogía, memoria e historia
}

\author{
El sufrimiento de un ser humano determina la \\ universalidad y la universalidad consiste en dejar \\ completo lo que está roto. Manuel Reyes Mate (2015)
}

En primer lugar, Muñoz (2016, p. 97) entiende que "la pedagogía como campo disciplinar pretende dar respuestas a las maneras de devenir seres humanos desde diferentes tradiciones”. Quiere decir que la tradición debe entenderse como aquella formación humana que busca una reivindicación y reestructuración de los procesos educativos de acuerdo con las prácticas pedagógicas; y también se interesa por las producciones de los saberes, legados y actuaciones propias de las sociedades. Además, se ocupa de aclarar todo lo referente a las tareas, objetivos o metas de la educación. Trata de asuntos que abren el horizonte de la formación (Bildung) y que tienen como punto de partida el cuestionamiento en torno a la finalidad de educar. Cuestión que se tratará más adelante en el capítulo: "Educar contra el olvido".

En segundo lugar, Benjamin (2008) entiende la memoria como aquella que mira hacia el pasado, y encuentra el estado de excepción permanente en el sujeto. En relación con lo anterior, Elizabeth Jelin (2002, pp. 9-10) dice que "la memoria tiene entonces un papel altamente significativo, como mecanismo cultural para fortalecer el sentido de pertenencia a grupos o comunidades". La autora hace referencia especialmente a los grupos oprimidos y silenciados, a un pasado común que permite obtener sentimientos de autovaloración y mayor confianza en el sujeto mismo y en otros. Por tanto, la memoria ha cuestionado desde siempre a la humanidad, pues lo que más preocupa es no recordar, no retener en la memoria. Además, en el plano cotidiano, la incógnita de por qué olvidamos nos acompaña permanentemente.

En tercer lugar, al entender las concepciones de pedagogía y memoria se comprenderá que se relacionan entre sí, desde la importancia de conservar los procesos educativos y de formación sin dejar de lado la praxis pedagógica, porque es en ella donde se evidencia el legado de una sociedad y al mismo tiempo el fruto de la formación. Así lo expresan Runge y Muñoz (2012, p. 78) al decir que cuando se refieren a la educación hablan de una práctica o una praxis, porque "toda praxis es un hacer, pero que no todo hacer es necesariamente una praxis". En otras palabras, no es de importancia si la acción se logra o si se realiza de manera exitosa, cuya finalidad se refleja en la acción misma. Asimismo, la praxis se resume en el hacer humano, a partir del cual se ve transformado lo humano mismo.

Ahora bien, la relación memoria e historia en Benjamin (2008) explica que, si es la memoria la que mira hacia el pasado y encuentra el estado de excepción permanente, no puede ser sólo la historia la que asuma tal particularidad. Su objetivo requiere el no olvido de la historia, pues se trata de una orden moral de prestar atención y de escuchar al testigo. El propósito está en la reelaboración de la historia con las voces oprimidas y silenciadas. La moralidad del testimonio se abre en el ámbito de la política, si se 
entiende que la memoria podría suponer una hermenéutica de la historia. La memoria sería entonces capaz de ocuparse de lo no escrito y de todo aquello que trae consigo al pasado, como aquella que comprende una filosofía de la historia y una propuesta política, que significa encontrarse el pasado no sólo como aquello que existió, sino como aquello que no alcanzó o cumplió sus objetivos; dicho encuentro sitúa de otra manera ante el presente mirar el pasado olvidado, pero también contemplar aquello que en el presente está en peligro de ser abandonado.

Siguiendo a Runge y Muñoz (2012), la historia no se puede comprender ni como historia de la dominación ni como destino, pues la libertad de la praxis humana solo es pensable como libertad histórica, o sea que a partir de su carácter imperfecto el ser humano se ve obligado a buscar su determinación mediante la transformación de su historia, por lo que toda historia como dominación o como destino va en contra de la libertad misma como praxis y de la praxis como libertad. Parafraseando a Jelin (2002), la relación entre la memoria y la historia es, hoy en día, una cuestión en la academia, y que la relación en torno a esta reflexión surge, por un lado, cuando la memoria es un recurso para la investigación en el momento de obtener o producir datos sobre el pasado y, por otro lado, cuando los estudios sobre la historia tienden a corregir memorias equivocadas o falsas. Esto se resumiría en que la memoria sería entonces objeto de estudio o de investigación.

Así como se expresó al inicio, la memoria en Benjamin (2012) es la que da la mirada hacia el pasado y encuentra el estado de excepción permanente en el sujeto, entendiendo por estado de excepción permanente esa manera de manifestar que el conocimiento político ha estado cerca del estallido y dominio manifestado como parte de un desarrollo positivo, que olvida los momentos duros y los considera como simples contingencias. Desde la crítica benjaminiana, la excepción se vuelve la regla debido a las condiciones de los sectores oprimidos y a la naturaleza de la dominación, es decir, se convierte en el dispositivo que mantiene unidos la violencia y el derecho, al tiempo que efectiviza aquello que rompe ese vínculo. Es el medio por el cual el derecho se refiere a la vida incluyéndola por su propia suspensión.

El interés del autor por el estado de excepción es el vencimiento de la dificultad producto de la violencia como promotora del derecho que, a su vez, permite conservarla, por lo que ella crea al derecho y lo mantiene al mismo tiempo y del mismo modo. Aquí el autor diría que los sujetos se ven afectados por la violencia: los que están con el que tiene el poder, estarían de alguna manera implicados con el gobierno mediante las normas, o sea, experimentan la decisión tomada por su líder, dirigido por la influencia de la norma. Para que el estado de excepción cumpla con su cometido de tener una parte de la sociedad sin ley, se hace necesaria la presencia efectiva de la ley misma, puesto que si todo fuera excepcional estaríamos en desconcierto, y lo que trata la reflexión benjaminiana es pensar los contenidos de un sistema legal que para los oprimidos se revela en un estado de excepción permanente. 
Entonces, la propuesta de Benjamin es detener un sistema que radica en suspender el derecho. Por tanto, la tradición de los oprimidos nos deja el legado de estar en un estado de emergencia en que vivimos, el cual es la regla. En este mismo sentido, en el texto Formación y praxis pedagógica revolucionaria. Los escritos de juventud de Marx y Benjamin, Hincapié García (2016a) expresa que:

Lo constante en la existencia humana ha sido la opresión y el sufrimiento. Por tanto, si causa asombro afirmar que las condiciones que han formado a los seres humanos responden a la dominación del hombre por el hombre, el asombro es únicamente una falta de sentido filosófico, puesto que allí donde algunos ven una excepción en esa imagen desgarradora de los hombres, el materialista histórico asume que esto ha sido una regla. (p. 263)

Esto también quiere decir que hasta ahora se imaginaba que el hombre procedía de una esencia superior que lo situaba por encima del mundo (la consciencia), pues ya se tiene claro que lo efectivo en el proceso de educar ha sido la dominación y la clase que posee los medios de producción es la que tiene el poder de establecer las condiciones como las únicas posibles y las más indicadas para la organización de la sociedad y de la formación de los hombres. En otras palabras, el proceso de formación y pedagógico ha sido marcado por la dominación, delegando la producción como el medio posible para responder a las necesidades y condiciones que establecen las clases dominantes para organizar la vida social y la formación de los hombres. Asimismo, Hincapié García (2016a), citando a Marx (2007), muestra que "la economía, el Estado y la cultura actúan para preservar condiciones de clase. La clase que domina es la clase que forma” (p. 263). De esta manera, se exige tener presente que la formación es un proceso de emancipación integral, política y ética, aplicable al margen de la lucha de clases, y que todo es político, todo repercute a favor o en contra de la liberación humana.

A partir de todo lo anterior, se ve con claridad el problema en la formación, es decir, el olvido en educación, al precisar que las prácticas educativas se basan en el olvido, en el sufrimiento, en el daño y en el carácter destructivo de toda intención humana. Desde ahí se dibuja a un hombre que olvida y que no se ha apropiado de las condiciones de su existencia, por lo que la verdadera formación no se ha producido, y ésta tendrá que realizarse a lo largo de la historia misma y por la actividad del hombre, pero una vez que se hayan recuperado las condiciones con las cuales se dé forma a una existencia emancipada. Por tanto, se dice que el hombre ha quedado en la prehistoria, pues se ha formado a sí mismo, pero no de una manera consciente, es decir, conforme a una idea emancipada de lo humano. Entonces, si el hombre no se forma conscientemente, no es más que pura "naturaleza domesticada" (Hincapié García 2016a, p. 264). Por tal razón, el hombre debe establecer nuevas formas para dar respuesta a sí mismo y a lo que le exige el mundo, sin dejar de lado la importancia de buscar los medios necesarios para una formación que sea capaz de emancipar lo humano.

Como se dijo anteriormente, el ser humano se forma a sí mismo, y para alcanzar la universalidad debe trabajar desde su propia actividad y consciencia, pues al hombre le 
corresponde elaborar las condiciones propias de su universalidad, de su ser y esencia. Por tanto, siguiendo a Benjamin (2010), Hincapié García (2016a) dice que "sólo tiene valor la educación que puede tomar posesión de su manifestarse; claramente, esto aparece en la puesta en escena de acciones que combaten un estado de cosas a transformar o intolerables" (p. 267). Se muestra que el problema de la formación apunta a que el hombre aún no puede dar cuenta de sí mismo porque está sujeto a nuevas determinaciones que el mundo moderno le propone y que por esto ha olvidado la realidad de su historia, y uno de los desafíos que se tienen hoy en el ámbito educativo es repensar la escuela en torno al hoy que se vive. Para dar más claridad a la idea, el autor también expresa que cuando el hombre se enfrenta a un ejercicio cotidiano mediante el cual produce los elementos necesarios para conformar su mundo, no solo está dando forma a los objetos que hacen parte de su ejercicio, sino que se está dando forma a sí mismo. Esta situación del ejercicio cotidiano y el darse forma a sí mismo por medio de él, produce en el hombre la consciencia requerida para lograr su propia libertad.

No obstante, Hincapié García (2016a), citando a Sánchez (1980), habla de "la praxis cuando la actividad de los hombres está orientada hacia un fin consciente” (p. 265). Quiere decir que la praxis es actividad a medida que el hombre la hace consciente desde su propio ejercicio y vivencia para poder transformarla. De esta manera, se puede dar un verdadero proceso de formación. En la perspectiva del problema por la formación, la sociedad actual se interpreta como contexto en crisis y en proceso de identificación de sí misma y con sus consecuencias. Esto apunta al requerimiento de una conducta autocrítica capaz de significar los problemas como oportunidad de cambio, de decisión, no como desalentadora o de desasosiego.

En la medida en que dicha contrariedad todavía se instaura en la praxis y en el pensamiento contemporáneos, se pretende hacer notar la importancia de un pensamiento pedagógico sobre principios y fundamentos en una época que está en crisis. En esta dirección, lo pedagógico así mismo conlleva una transición (crisis), porque los fines educativos modernos ya no son sostenibles en el contexto pedagógico, cuando la idea de formación humana entra en crisis, se deshace y se disuelve, y la práctica educativa pierde legitimidad y justificación. En este contexto, la decisión pedagógica podría girar en torno a la pregunta por la formación y la educación no afirmativas, es decir, una formación de subjetivación que tenga como propósito concepciones humanas no dogmáticas ni normativas.

Se puede decir que estamos vivenciando una gran aceleración de la historia, lo cual hace que la transferencia de conocimientos y experiencias de nuestros ancestros, de generación en generación, sea reemplazada y modificada por una aplicación de nuevas generaciones, que hacen que ya no pueda efectuarse por medio de la tradición histórica de nuestros antepasados, por lo que cada vez más, las generaciones se separan las unas de las otras por la influencia del capitalismo. Entonces, el problema solo se puede resolver mediante la transformación o transición a un nuevo modo de aprendizaje, dejando de realizar lo impuesto. Para resolverlo, se debe trascender 
a su actual nivel de desarrollo incompleto y unidimensional, y se debe hacer esto si se desea contribuir a la solución de los problemas de la sociedad. El caso es que su capacidad para transformar lo impuesto está limitada a la falta de reconocimiento de la sociedad misma, a la cual se pertenece, y por las limitaciones correspondientes de las personas que ésta ha adaptado. Evidentemente, cualquier progreso que pueda hacerse será lento y pausado.

Dentro de esta reflexión es importante decir que se puede tomar el problema como un evento posible de instaurar una sociedad a la altura del hombre y una oportunidad de crear una educación con sujetos libres, es decir, una pedagogía que origine acuerdos entre la transmisión y la emancipación, una pedagogía donde el sujeto pueda interactuar de manera inmediata con la verdad. Por todo lo anterior, es que se dice que la crisis se centra en la ingenuidad de las civilizaciones, en su falta de conciencia sobre los orígenes de su propia razón, explicando, de esta manera, una interpretación antropológica de un ser humano actual que es ingenuo. Viendo la rigurosidad del problema de la formación y de la práctica pedagógica, se debe mostrar a la sociedad la necesidad de los sentimientos de comunidad y la pobreza de la consciencia de sí mismos (Hincapié García 2016b). Puede decirse que el hombre actual ha estado sujeto a los pensamientos que tengan de él, no a los que él puede tener por sí mismo, para poder transformar en medio de la lucha y el cambio. Lo que realmente se pretende es que el sujeto realice todo lo contrario a lo anteriormente relatado, es decir que el hombre esté en la capacidad de pensar por sí mismo y que no esté sujeto a lo que otros puedan hacer por él.

A partir de todo lo anterior, afirmo que la memoria conserva un privilegio que la historia no puede quitarle, y es el de situar la propia historia como disciplina retrospectiva en el movimiento de la conciencia histórica. En ese sentido, procede de una abstracción de la dimensión del pasado. De ahí que la temporalidad del historiador no escape a la constitución de toda conciencia histórica, pues no solo los hombres del pasado, imaginados en su presente vivido, han proyectado cierto porvenir, sino que su acción ha tenido consecuencias no queridas. Esta es la tarea de quienes podrían llevar a la formación la solución al problema de la práctica pedagógica: la de despertar y reanimar estas promesas incumplidas. En cierto sentido, la tradición y la memoria son fenómenos que dependen el uno del otro y que poseen la misma estructura narrativa. Pero hay que aprender, mediante la presión de la crítica histórica, a desdoblar el fenómeno de la tradición, y que después de todo no debemos olvidar las promesas incumplidas del pasado, pues tenemos primordialmente una deuda que saldar con ellas.

Ahora bien, el deber de la memoria parece consistir en luchar contra el olvido, pues se presenta como una amenaza cuando trata de recuperarse el pasado. El historiador no tiene que rehabilitar solamente lo que tuvo lugar, sino lo ocurrido en el pasado. A partir de ahora, no hay por qué decir que la huella repite únicamente el enigma de la señal o de la marca. Al sustituir a estas últimas, el testimonio desplaza el problema de la huella. La discusión precedente implica que el tratamiento por separado del pasado 
desemboca en una situación problemática, pues solo se goza de la memoria a la hora de saber si algo sucedió realmente con anterioridad.

Nuestra historia muestra que el paso generacional del hombre responde en gran medida a los modos en los que cada generación ubica su memoria, es decir, los movimientos sociales en contexto, los cuales reivindican un pasado histórico para elaborar sus reclamos, exigir su lugar o demandar atención a sus demandas. En estos actos la memoria construye una imagen de sí misma alimentada de modo selectivo por datos significativos de las generaciones anteriores, dichas imágenes suelen construirse narrativamente, aunque la intención es la misma: desarrollar una imaginación generacional que les permita la distancia con otras y transmitir un sentido de lo común a quienes temporalmente comparten su espacio y contexto. Hasta aquí la memoria, como reconstrucción del pasado que se hace desde el presente, pretende dar forma a diversas narrativas que filtran las interpretaciones del pasado, por lo cual, es importante prestar atención a la forma oficial de la historia en la vida del hombre.

\section{Educar contra el olvido: duelo público}

La redención, si se permite la licencia, es la lucha por realizar en el mundo un ideal que haga justicia a todo el sufrimiento que ha sido la regla para los hombres. Alexánder Hincapié García

Después de haber visto esta necesidad de formación en el hombre y de saber que nos encontramos en un problema actual por no saber dar cuenta de nosotros mismos, se hace necesario continuar con la relación conceptual memoria e historia, para poder dar cuenta de esta reflexión característica que gira en torno a las necesidades de formación del ser humano y que no se debe olvidar el pasado sin preocuparnos por las huellas que dejaron los oprimidos. Por tal motivo, Benjamin (2012) explica que "la función de la memoria es la protección de las impresiones, pues el recuerdo tiende a su deterioro. La memoria es en lo esencial conservadora mientras que el recuerdo es destructivo" (p. 213). Quiere decir que la memoria conserva y el recuerdo destruye, además, no todo lo pasado le sirve a la vida, y para que ella pueda desarrollarse el hombre debe apropiarse de las cosas útiles volviendo al pasado y desechar lo poco servible para transformar su presente. Por eso el porvenir nuestro no está en el futuro sino en el pasado. En otras palabras, la memoria estaría en la capacidad de ocuparse de lo no escrito, sino de los recuerdos.

Desde esta perspectiva, el deber de memoria en Benjamin está enlazado con la injusticia que se encuentra en la cancelación del derecho de las víctimas, así como también con la reorientación de la historia desde el centro mismo de los testimonios. Al ubicar el testimonio como principio de conocimiento y el testigo como intérprete de la historia, memoria y justicia quedan unificadas fielmente. A partir de aquí se hablará de tradición, debido a que el testimonio es un imperativo moral de las 
víctimas, porque el olvido no es un componente más de la lógica progresiva sino el fundamento del propósito de la modernidad.

Entonces, en la concepción benjaminiana se explica que las distancias entre historia y memoria podrían acortarse si el pensamiento se acerca a la conmemoración, asumiendo con la certeza colectiva que ese lugar de conocimiento se recupera del olvido y de la tradición. En este sentido, el autor habla del presente como aquello que implica una revolución en la que el pasado se ve amplificado por el mismo presente, por lo que el presente mismo ubica el suceso, lo ocurrido en la historia anterior o posterior, no solo instaurándose como fuente de conocimiento, sino también como una forma de recuerdo.

En consecuencia, Hincapié García (2016a, p. 269) dice que "la redención, si se permite la licencia, es la lucha por realizar en el mundo un ideal que haga justicia a todo el sufrimiento que ha sido la regla para los hombres". Aun se refleja que el hombre todavía no despierta a la consciencia de su existencia histórica. En otras palabras, el hombre todavía desplaza las preguntas por sí mismo, esto es, por su formación, hacia un mundo de fantasía del que se supone que proviene. El compromiso de las actuales generaciones no es solo con el presente o con el futuro, sino que el compromiso es hacer justicia al pasado, continuar con la lucha de realizar los propósitos por los cuales los vencidos fueron derrotados y desarrollar una consciencia histórica que nos permita redimirnos con nosotros mismos. No se lucha solo por cosas materiales, se lucha por alcanzar y desarrollar una vida buena, la cual haga justicia a otra idea de hombre.

De antemano, el mismo deseo por lograr los bienes materiales está cargado con el conocimiento de saber que dichos bienes se han conseguido con el sufrimiento de los vencidos; así, pues, esto impulsa la lucha del hombre por un ideal político y ético, que no solo tiene como objetivo recuperar la memoria de los vencidos, de los que sufrieron, sino también los proyectos a los cuales fuimos sometidos a olvidar (Hincapié García, 2016b). Teniendo en cuenta lo dicho en el apartado primero del artículo, en Benjamin (2008) la relación establecida entre memoria e historia funda un nuevo concepto de historia basado en la rememoración y la redención. Por un lado, se entiende por rememoración aquella mirada específica al pasado, una construcción del presente desde el pasado, es decir, creación del presente con elementos del pasado, y para que esta tenga sentido debe darse un encuentro entre determinaciones del pasado y del presente. Por otro lado, siguiendo a Löwy y Benjamin (2003), se explica que la redención exige la rememoración del pasado, sin hacer diferencias entre lo vivido por el hombre.

Hincapié García (2016b, p. 53), en su texto “Imaginación política”, historia e impulso anti-narrativo. El retorno revolucionario de Walter Benjamin (1892-1940)”, expone la idea de rememoración como aquella que revela todo lo que "ha sido ignorado o lo que ha sido rechazado...”. El autor quiere dejar claro que mientras el sufrimiento de los vencidos sea ignorado o negado no puede haber justicia alguna al pasado, pues los 
muertos, los caídos o vencidos no podrán descansar en paz y los vencedores no dejarán de cumplir con su función, la cual consiste en vencer. En este sentido, el olvido del sufrimiento de las víctimas implica que no hay liberación posible, pues es indispensable salvar del olvido cada intento liberador, reconociéndolo y rememorándolo por igual. La redención del pasado es la realización y la reparación según la imagen que tenga el ser humano de sí mismo, pues se da si el pasado toma una nueva forma y reestructura al presente en relación con lo prometido, lo cual podría haberse olvidado, pero que reinscrita en el presente ilumina lo actual de manera innovadora según la imagen de hombre y de cada generación.

Desde el sentido benjaminiano, se reflexiona que la historia no es solo la recuperación del pasado, sino primordialmente la reparación o transformación del presente. En otras palabras, el pasado no está cerrado, está a la espera de ser rescatado y reconocido por nosotros mismos. Así mismo sucede con el acto de educar, debemos estar dispuestos a reparar lo roto y transformarlo, pues el pasado está en nuestra espera, porque se debe reconocer y recuperar. En consecuencia, Fullat (1992, p. 145) afirma que "educar es producir al ser humano". O sea, el hombre en lo individual y colectivo está siempre por hacer. Por esto desde la educación se debe recuperar lo que ha sido abandonado por otras generaciones y resignificarlo en el presente; de este modo, se podría decir, se hace justicia al pasado en el presente y se educa contra el olvido.

Hasta aquí, todo lo anterior genera una transformación activa del presente desde el acto de educar, y esa transformación implica una mirada crítica del presente mismo, reconociendo nuestra tarea: la de traer al frente el verdadero estado de excepción permanente, lo que permitirá mejorar nuestra lucha contra el pasado teniendo en cuenta la memoria de los vencidos. Se pretende que en la educación se constituyan nuevas pedagogías fuera de los límites de la opresión, del condicionamiento, de la disciplina y del control, porque la educación se debe orientar a las nuevas formas de pensamiento, donde el aprendizaje genere nuevas experiencias, de acuerdo con las necesidades de la época, para que el sujeto construya su propio conocimiento con libertad y produzca relaciones oportunas con los otros, dejando a un lado la homogeneidad para dar entrada a la heterogeneidad y singularidad de cada ser.

Con la preocupación del mundo actual, Butler (2006) en su texto Vida precaria. El poder del duelo y la violencia, habla del duelo y de sus funciones en un mundo atravesado por manifestaciones punzantes y masivas de creciente violencia y vulnerabilidad. Para entender la dinámica del duelo, la autora propone considerar la central filiación que relaciona al yo y al tú, porque estos dos vínculos humanos se encuentran basados también desde el pensador Lévinas en Butler (2006), cuando explica que la precariedad de la vida empieza con la vida precaria del otro. De ahí que la vulnerabilidad constituya la más básica y radical de las condiciones humanas, y que se debe reconocer y mantener esa vulnerabilidad para protegerla, pues se debe conservar y reproducir. Sólo en la vulnerabilidad y en el reconocimiento de las distintas maneras en que el otro se separa de mí, es donde se hace la invitación al desconocimiento de sí mismo. Por ende, se diría que el duelo se conoce como el proceso psicológico y social 
a través del cual se reconoce pública y privadamente la pérdida del otro, porque es la perspectiva más obvia de la vulnerabilidad y de la condición de lo humano. Así, pues, el duelo busca hacer conciencia de la condición de lo humano y al mismo tiempo crea una modificación de sí mismos. Se requiere de la aceptación de lo vivido, porque este se pudo vivir de otra manera y en otro contexto. En otras palabras, cuando el hombre sea capaz de reconocer la vida vivida del otro, se vuelve más vulnerable y más humano.

Continuando con esta reflexión, la vulnerabilidad como condición humana y acción desde lo educativo pretende replantear las bases de la comunidad política, como proponer una ética de la no violencia. De este modo, la autora impulsa la necesidad del hombre en su deseo de ser reconocido por otros, creando la ilusión de una identidad ante la sociedad; es así como esta privación del mismo deseo genera violencia, debido a que el hombre, en su obsesión de poder, requiere el reconocimiento constante para mantener su carácter de altivez y satisfacción de su propio deseo. Visto de esta manera, si el hombre no es vulnerado en su deseo de reconocimiento ante las multitudes estaríamos hablando, según la autora, de una no violencia, por lo que la necesidad de reconocimiento del hombre debe provenir más bien de un aparato estatal que posibilite la identidad de la condición humana frente a los otros.

Del mismo modo, cuando somos conscientes de esta vulnerabilidad se pueden encontrar soluciones, pero si las negamos se fortalecerían los argumentos en contra de la solución. Por eso es necesario reconocer la vulnerabilidad, porque si el hombre tiene esta capacidad de reconocimiento se podría hablar así de una condición humanizante, por lo que el hombre puede reconstruir la vulnerabilidad. Por este motivo, el yo y el tú necesitan ser reconocidos de manera recíproca, porque ambos tienen la necesidad del reconocimiento, lo que permite una transformación y futuro en relación con el otro. Asimismo, Piñeres Sus (2016), en su texto "Antropología e idealidad. Algunas reflexiones sobre crueldad y superfluidad", dice que la violencia y la crueldad son en sí mismas un problema antropológico, porque las ideas de violencia se concentran en la idea misma de humanidad, ya sea para imponer un concepto normativo de lo humano, o para invalidar las formas de vida que se alejan de la economía obligatoria que ofrece el Estado.

En cuanto a la crueldad, la idea de humanidad se ve funcionar de manera heterogénea, es decir, gran parte de sus cosas se ven funcionar de manera imponente sobre el sujeto. Entonces desde aquí se dice que "la crueldad aparece bajo el impulso de reducir al hombre al desecho” (Piñeres Sus, 2016, p. 24). De este modo, la crueldad como reducción de lo humano a mero desecho aparece legitimada en la historia de instituciones de poder, imponiendo un modelo antropológico obligatorio. Entonces la crueldad lleva consigo la destrucción de la individualidad y la consecución de una nueva, a través de las formas de poder que ofrece la época.

A partir de lo anterior, se puede decir que el proceso educativo del hombre debe poner la formación propia del sujeto en relación con la del otro, porque la formación propia del sujeto supone al otro de manera recíproca y relacionada. Entonces, parte del yo es 
reflejo del tú, porque hay huellas del otro que hacen parte del sí mismo, lo que concibe que en realidad no se pueda ser consciente por completo de sí mismo. Es decir, aquí es donde se manifiesta el acto de educar contra el olvido, las huellas del otro también hacen parte del yo al mismo tiempo. En este sentido, el hombre no puede conocerse a sí mismo ni conocer sus diferencias respecto al otro. Esto requiere cuestionar la formación cultural que al día de hoy nos permite pensar lo humano, porque si las humanidades tienen algún futuro como crítica reflexiva ante la cultura, se debe a que la crítica cultural tiene la responsabilidad de regresarnos y repensarnos con relación a lo humano.

En esta misma línea, el concepto de violencia en Manuel Reyes Mate (2003, p. 89) se describe con la significación de Auschwitz, es decir, "la barbarie nazi contra el pueblo judío, nos cae lejos. Lejos en el tiempo, lejos en el espacio y, más lejos aún, en la sangre". Es un momento central de la historia del siglo XX que nos afecta. Es la fragilidad en nuestro tiempo, donde se producen barreras culturales que conducen a la decadencia social y al fracaso, propiciando en el fondo de cada ser humano la barbarie. Como se puede observar, Auschwitz lleva a cabo un rompimiento epocal que expone una dificultad de identidad por la problemática moral del momento, la cual no se advirtió en otros tiempos históricos. Digamos que Auschwitz es la imagen de una barbarie aterradora, pero que culmina un proceso histórico de violencia. Quiere decir que es un hecho singular, desconocido y lleno de maldad, que no surge de la nada ni por sí mismo, sino que es el producto de ciertas eventualidades que sucedieron desde muy atrás en la historia.

Se puede decir que de Auschwitz podemos conocer casi todo por su información global, pero no lo podemos comprender porque no se reconocen las causas y acciones históricas que de una manera lógica lleven a una respuesta a favor de la historia del ser humano. Recordar Auschwitz lleva consigo la construcción de la memoria que envuelva y sensibilice el recuerdo específico de ella. A eso quizá se refiere Adorno (citado por Mate, 2003) cuando expresa que no se queda en la memoria de Auschwitz, sino que pone como condición redirigir el pensamiento y el obrar. En otras palabras, se invita a la creación de una cultura de la memoria como presupuesto de la educación:

Adorno recuerda que "la exigencia de que Auschwitz no se repita es la primera de todas las que hay que plantear a la educación [...] cualquier posible debate sobre ideales educativos resulta vano e indiferente en comparación con esto: que Auschwitz no se repita". (Mate, 2003, p. 89)

Esta afirmación es directa y trae consigo la metáfora de que no se puede silenciar, admitir o justificar aquello que se genera dentro de la civilización: la barbarie y su consecuencia. Es decir, la realidad no son los hechos, pues la memoria cuestiona lo presente, se trata de entender la realidad sin que nada se pierda, o sea, exigir en el conocimiento; pero para esto es necesario el punto de vista de los vencidos y de los vencedores, porque la historia se escribe sobre los hechos y no sobre las ausencias. Lo anterior explica que no solo en la barbarie murió el judío, sino que también murió 
el hombre y que, ejerciendo esa barbarie, nos hemos empobrecido en humanidad y somos ricos en la misma intolerancia, y es en esa misma medida que debemos calcular nuestra pobreza en humanidad. Asimismo, venimos de ese pasado y si Auschwitz significa algo, es visibilizar el sufrimiento sobre el que se ha construido la historia.

El deber de la memoria entonces será una invitación al combate contra la barbarie propia o ajena. Además, se invita a recordar a través de la educación el pasado, desde las huellas y marcas que han dejado los oprimidos y las víctimas. En consecuencia, Auschwitz en la educación reconoce la fragilidad de la época, sus tradiciones que forman la humanidad, las cuales son las grandes tradiciones occidentales. El sentido de la educación es enfrentar la barbarie, o sea, enseñar a vivir humanamente. Tal consideración solo será posible si se trata el problema, abiertamente, sin miedo de chocar con poderes establecidos de cualquier tipo, sin perder de vista que el hombre convive consciente o inconscientemente con la barbarie que amenaza al mundo de hoy.

Se hace necesario entonces participar de una sociedad más justa donde las normas establecidas se puedan cumplir, porque si queremos conocer el pasado debemos conocer la memoria como ausencia que cuestiona lo presente. Debemos reconocer nuestra condición de humanidad. Hacer justicia es aliviar todos los daños que la violencia ha causado a la sociedad, por eso ella misma genera indiferencia entre los mismos hombres, porque la memoria carga con el peso del pasado, del recuerdo, del mismo pecado y es donde el perdón la hace libre, para que, desde allí, se puedan generar nuevos proyectos para establecer un futuro próspero y se pueda enmarcar un nuevo comienzo dirigido desde la educación y formación del hombre.

En cada momento del presente, así como lo expresa Hincapié García (2016b, p. 51), "hay una leve fuerza mesiánica que puede hacerse funcionar, una fuerza mesiánica que puede ayudarnos a actuar distinto". Para el autor, significa reconocer que el materialismo histórico puede también ponerse al servicio del conformismo y de la sumisión, suscribiendo el ideal de progreso, y que el capitalismo, por la contradicción de sus elementos, se destruiría a sí mismo dando paso a la sociedad producida por una superación desde la reflexión (dialéctica). Entonces, en este caso el materialista histórico no debe esperar a que ello suceda, sino que debe comprometerse con la redención del pasado, destruyendo en el presente la idea de progreso.

A partir de todo lo anterior cabe preguntarnos: ¿Podemos educar contra el olvido? La respuesta a esta pregunta la encontramos cuando comprendemos que desde la memoria podemos dar vuelta al pasado y recuperar lo que se ha perdido u olvidado. Sí, hay respuesta a dicho interrogante, desde que seamos conscientes de nuestra historia, desde que continuemos con la lucha que cesaron nuestros vencidos, muertos y víctimas; desde que seamos capaces de reconocernos a sí mismos y en el otro al mismo tiempo, desde allí podremos enfrentar y reconstruir la nueva época que se nos ofrece. Entonces la respuesta a tal interrogante está en el hombre mismo, cuando se hace consciente de su propia formación, cuando dejemos de sentir sometimiento y digamos sin pudor todo aquello que nos aqueja y oponer resistencia ante el silencio, 
y una vez más, cuando nos hacemos conscientes de lo que falla y su consecuente necesidad de modificación.

Así pues, el recuerdo que experimentamos no es solo el carácter pasado de las cosas ausentes, sino el propio tiempo, lo destacable en el modo de aprender. No ha de hablarse de un desplazamiento, pero sí de un reconocimiento, el que brota de todo un trabajo, también del olvido, para hacer resurgir nuevas líneas de conocimiento para el hombre. Con ello nos vemos en la necesidad de reelaborar permanentemente el sentido de los acontecimientos que, como los textos, no se reducen a su materialidad. Si hemos de aprender del futuro es al precio de escribir el pasado y podernos reinventar constantemente a nosotros mismos. La carga del pasado que recae en el futuro insta a incorporar la noción de deuda, que ya no es pura carga sino recurso, necesidad de relato. Gracias a aquello por lo que podemos ser, no todo se reduce a lo que ya ha sido. Ello ofrece todo un acopio de compromisos con el presente en el que se precisa una nueva representación y recreación de la realidad.

La lectura que se nos propone confirma lo que se da entre la memoria y la historia, que en este contexto no es solo retrospectiva, sino, asimismo, recreadora. Además, la historia no es una simple cuestión de huellas, es un asunto de deuda, la que se reclama con el pasado. Dicha deuda obedece a que no se nos ofrece simplemente "lo que ha sido", sino que se nos sitúa en un espacio de confrontación de diversos testimonios y con diferentes grados de nivel reflexivo. Hasta aquí, lo que hemos aprendido o adquirido puede llegar a perderse, por eso hemos de conservar las huellas. El archivo histórico es un buen ejemplo, pues, hay que transformar los restos históricos en archivos dentro de un marco institucional. El trabajo del recuerdo consiste en preservar los restos del pasado.

\section{Conclusiones}

Lo que somos y lo que sabemos está realizado desde el recuerdo y de la memoria, es decir, somos lo que sabemos, pero se logra sólo si nos acercamos al sufrimiento de nuestros antepasados, los ausentes y los invisibles, los cuales han sufrido la injusticia y la violencia. Por ello, en nombre de las futuras generaciones, no cabe el olvido de un pasado y un presente que no aprecia el valor de la memoria y que sigue dejando en el pasado a las víctimas del sufrimiento. Para hacer visible lo que se ha dejado atrás es necesario mirar el mundo con la mirada de las víctimas, de los vulnerados, y reivindicar el derecho a la memoria como un deber de justicia con los olvidados. De ahí que educar en la memoria de las víctimas constituya un deber ineludible de la educación, o sea, educar contra el olvido.

La educación en las sociedades democráticas debe estar dirigida al educar desde una mirada sensible hacia el dolor y la injusticia de quienes la han padecido y vivido, además se debe pensar en lo que nos rodea, haciéndonos conscientes de lo que falla y su consecuente necesidad de reconstrucción, porque se podrán escuchar las voces 
de los otros que han sido abatidos por el problema postmoderno y que han sido sometidos al silenciamiento. Esto nos lleva a pensar lo roto, no sólo como aquello que se dejó de hacer o de pensar, sino como algo que nos exige un cambio de mirada y explorar críticamente lo que se dejó atrás y recuperar en ello el potencial que trae el presente.

Así, superar la tradición no es reconocer y dejar lo que lleva la libertad del hombre, sino centrar la mirada para ver la posibilidad de encontrar otras respuestas al mundo de hoy. De este modo, el compromiso de las nuevas generaciones no es solo con el presente, es con el imperativo moral de hacer justica al pasado, de crear en ellas la consciencia histórica del daño y del sufrimiento, como también de la capacidad de repararlos, lo que lleva a luchar por la realización de los propósitos por los cuales los vencidos fueron derrotados y abrir la posibilidad de integrar lo nuevo, sin dejar de comprometernos con los objetivos que los vencidos no pudieron llevar a cumplimiento.

\section{Referencias}

Andréu, J. (2000). Las técnicas de análisis de contenido: una revisión actualizada. Sevilla: Fundación Centro Estudios Andaluces.

Benjamin, W. (2008). Tesis sobre la historia y otros fragmentos. (Introducción y traducción de Bolívar Echavarría). México: U.A.C.M.

Benjamin, W. (2012). Sobre algunos motivos en Baudelaire. Libro 1|vol.2. Madrid: Abada. Cap. III.

Butler, J. (2006). Vida Precaria. El poder del duelo y la violencia. Buenos Aires: Paidós.

Escobar García, B. e Hincapié García, A. (2017). Dar la palabra. En torno al lenguaje de los niños y las niñas en la cárcel. Revista Latinoamericana de Ciencias Sociales, Niñez y Juventud, 15(1), 59-70.

Fullat, O. (1992). La educación y sus saberes. Educación, 1(2), 145-166.

Hincapié García, A. (2016a). Formación y praxis pedagógica revolucionaria. Andamios. Revista de Investigación Social, 13(32), 257-279.

Hincapié García, A. (2016b). "Imaginación política”, historia e impulso antinarrativo. El retorno revolucionario de Walter Benjamin (1892-1940). En B. Escobar García y A. Hincapié García (eds.), Modernidad y Política. Sobre la pregunta antropológica. Medellín: Unaula.

Jelin, E. (2002). Los trabajos de la memoria. Madrid, Buenos Aires: Siglo XXI.

Löwy, M. (2003). Walter Benjamin: Aviso de incendio. Una lectura de las tesis "Sobre el concepto de historia”. Buenos Aires: Fondo de Cultura Económica.

Márquez, J. y Vélez, I. C, (2017). Globalización neoliberal y crisis de la educación. (Tesis de maestría). Universidad de San Buenaventura, Medellín. Recuperado de http://bibliotecadigital.usb.edu.co/handle/10819/4200 . 
Mate Rupérez, M. R. (2003). Por los campos del exterminio. Barcelona: Anthropos Editorial.

Mate Rupérez, M. R. (2015). Notas sobre el Seminario Historia, Memoria y Reconciliación. Seminario ofrecido por la Universidad de Antioquia y la Universidad de San Buenaventura.

Muñoz, D. A., Cano, C. T., Pérez, G., Ríos, J. I., Giraldo, J. L., Escobar, J. V. y Ramírez, L. E. (2010). El compromiso social fundador y las propuestas pedagógicas motivadas por las exigencias legales, conceptuales y contextuales en la última década de las facultades de educación adscritas a Ascofade. En Una mirada hermenéutico - reconstructiva sobre el quehacer de las facultades de educación adscritas a Ascofade. Capítulo Antioquia-Chocó (pp. 17-41). Bogotá: Ascofade.

Muñoz, D. A. (2016). Una aproximación filosófica y pedagógica a la obra de Paulo Freire. Hacia una antropología filosófico-pedagógica latinoamericana. En B. Escobar G. y A. Hincapié G. (eds.), Modernidad y política. Sobre la pregunta antropológica (pp. 71-105). Medellín: Ediciones Unaula.

Piñeres Sus, J. D. (2016). Antropología e idealidad. Algunas reflexiones sobre crueldad y superfluidad. En B. Escobar G. y A. Hincapié G. (eds.), Modernidad y Política. Sobre la pregunta antropológica. Medellín: Unaula.

Prior, Á., Bello, E., Capillo, A., Guillamón, F. J., Lrite, J., Peñalver, F. et al. (2002). Nuevos métodos en ciencias humanas. Barcelona: Anthropos.

Runge Peña, A. K. y Muñoz Gaviria, D. A. (2012). Pedagogía y praxis (práctica) educativa o educación. De nuevo: una diferencia necesaria. Revista Latinoamericana de Estudios Educativos, 8(2), 75-96. Recuperado de: http://www. redalyc.org/articulo.oa?id=134129257005 